\title{
Pandemic enforcement: E-working and e-learning joined their efforts globally
}

\author{
Michal Beno ${ }^{1, *}$, and Jozef Hvorecky ${ }^{1}$ \\ ${ }^{1}$ Institute of Technology and Business, Okružní 517/10, 37001 České Budějovice, Czechia
}

\begin{abstract}
Research background: E-learning and e-working collaborated on a voluntary basis for long. The global COVID-19 lockdown enforced them to a rapid worldwide transition to work, teach, and learn from home.

Purpose of the article: Our main aim is to identify the interrelations between e-learning and e-working during the pandemic period. Considering e-working as the $1^{\text {st }}$ pillar and e-learning as the $2^{\text {nd }}$ pillar, we ask: What structure can we build above them? What are its global features?

Methods: Our study uses a comparative analysis. We juxtapose results of a survey among 120 full-time Austrian e-workers on their experience with eworking and e-learning with one of 172 university teachers in Czech and Slovak Republic. Our findings can be applied far beyond their local frontiers.

Findings \& Value added: Among the employees, $40 \%$ are facing some difficulties with face-to-display work. Only $40 \%$ of the employees would like to work at cubicles after the pandemic, $30 \%$ prefer hybrid (combination of online and on-site) and 30\% full e-working. $75 \%$ of e-workers participated in online courses. $45 \%$ of them wander whether schools and universities are prepared for e-learning. $60 \%$ highlight that education system needs to invest in its ICT to be better prepared for online education; $70 \%$ recommend hybrid education as the optimal solution. $40 \%$ of them believe that online learning is more challenging compared to traditional onsite learning. Some of their suggestions contradict the opinion of university educators. A majority of them considers online education as a temporary replacement.
\end{abstract}

Keywords: e-learning; e-working; hybrid working and education; globalization of work and education

JEL Classification: $A 20 ; H 12 ; I 25 ; M 53 ; O 35$

\section{Introduction}

The recent century has introduced myriads of technological innovations. Today, technology enables mankind to connect each other and collaborate anytime, anywhere using almost any

${ }^{*}$ Corresponding author: beno@mail.vstecb.cz 
device. Communication and collaboration tools operated by non-collocated employees indicate that elements of distributiveness. Virtuality have become a common feature of contemporary organisations (Henry et al., 2021).

This stepwise process has been hurried up by COVID-19. The worldwide lockdown of educational organizations and workplaces enforced them to respond the challenge. The EU statistics shows that between 2012 and 2019 the average ratio of employed persons working from home fluctuate about 5\%, in 2020 it raised to $12.0 \%$. Similar trends are typical for all countries, including the ones we surveyed: Austria, Slovakia and the Czech Republic. In Austria the ration fluctuated about $10 \%$ for years - then it jumped to $18.1 \%$. In Slovakia, the number of grew from $3.7 \%$ to $5.7 \%$. Between 2012 and 2019, the ratio grew slowly from $3.4 \%$ to $4.6 \%$ in the Czech Republic; in 2020 , it quickly jumped to $7.2 \%$. From a researchers' point of view, similar moments offer an extensive room for their studies. In our paper, we concentrate on two major fields: home offices and education.

As stated by Beňo et al. (2021, p. 97), on the rise of pandemic all organizations (big, small, global or local) found themselves under the same conditions. To survive, they have compelled quick adaption to the virtual workplace (e-working) and virtual classrooms (elearning). The same effect was visible at universities. To continue their function, they moved to their online mode. None of these concepts is entirely new. The novelty lies in the fact that in the environment of social distancing, working, teaching and learning they become unavoidable, essential and a new standard. E-commuting, formerly e-working, raised over last years. As a rule, the type of work connected with staying at home was primarily connected to major projects/tasks (Beňo, 2021, p. 25) and not always welcome. According to Hopkins and McKay (2019), regardless many reasonable economic, social and environmental benefits, the anywhere working acceptance in Australia rests small.

The pandemic facilitated a variety of pessimistic views. Karim et al. (2020) perceive COVID-19 pandemic as enhancer of worklessness, consumption of savings deposit, declining of the country's payment income. At the same time, Madero Gómez et al. (2020) analysis validates a relationship between COVID-19 stress and its impact on the workforce. They show that to compete in the modern economy, our society needs well educated and well trained workers. A progress based on skilled workforce proposes a long term solution (Kartim et al., 2020) and includes college education as an essential for individual and institutional competition. Workforce is a capital which has to be steadily developed and educated (Stofkova and Sukalova, 2020). The question is what can higher education do to prepare students for these kinds of positions? One can suggest to include online education among compulsory (but not exclusive) teaching methods (Eurostat, 2020). Anttiroiko (2021) highlights that COVID-19 actions by Asian and Western countries vary due historical, cultural and political dissimilarity.

Education as a human resource investment diminishes poverty and income inequality (Roca-Puig, 2019). To invest into it does not mean changing the content in courses or programs offered by colleges or universities only. It should address their proposed format, too. As universities do not exist in vacuum (Beňo et al., 2019), all applicable modes should be introduced: in person, fully online, and hybrid - naturally, with the respect to the course specifics.

In regards to these threats, we developed two different surveys and placed them in collaboration with Austrian professionals and Czech and Slovak educators. The survey studied employees' and educators' needs, intentions and the efficacy of organizational and institutional changes and challenges at workplace and in virtual educational environment. We tried to understand the issues and challenges the workers and educators have faced as well as to learn what their organizations and educational institutions have modified already. 


\section{Methods}

An unauthenticated, self-managed survey instrument was developed to collect necessary information from workers and educators about their work and educational experiences during COVID-19. Two groups of data were independently collected: full-time professionals from Austria and educators from Czech and Slovak Republic. Due to the limitations of the lockdown, the authors decided to execute all communication online. As a part of it, all participants were fully informed about the confidentiality, privacy, sensitivity and data protection during after the survey. A consent form was issued and completed by every participant. The survey was realized via online platform and the link was distributed through authors' personal contacts. Additionally, the participants shared the link with their network or pool of respondents.

Both questionnaires were tested with a group of related respondents before their finalization. These respondents did not participated in the final run.

The questionnaires started with demographics such as their age, gender, marital status, parity. The educator's demographics asked the country and type of university instead of their marital status and parity. The core questions examines their professional activities i. e. faceto-display work and online learning. The findings from the survey answered following research questions: Is e-working working? Is online education an accurate substitute for traditional education?

Initially, the surveys were fully independent to each other. Unexpectedly, their results presented several similarities. Thus, we decided to juxtapose them. To do so, the descriptive method has been implemented to compare the observations of both work and educational processes with focus on their crucial ties.

\subsection{Samples}

In our analysis, we study the relationship between universities and companies as a pair of potential partners in the field of (online) education. We consider their key players in this partnership: their educators as the service producers and the employees as its receivers. We study the conditions in which they act in order to facilitate their potential partnership.

\subsubsection{Educators}

The total of 172 educators responded (67 from Czech universities and 105 from Slovakian ones). There are the key attributes of this group:

- 146 educators come from public universities, 26 from private ones;

- There were 108 females and 64 males;

- The age group of 40-60 year old ones has got 88 members, the 20-39 group 44 persons, the $60+$ group counted 40 educators;

- 154 teachers work full-time and 18 part-time.

\subsubsection{Full-time professionals}

120 Austrian employees were selected, made 68 male and 52 female. Further sociodemographic data included:

- $\quad$ The age group of 30-44 year old ones has got 58 members, the 20-29 group 25 persons, the 45-59 group counted 37 employees;

- 67 out of all respondents were single (divorced, separated), 53 married;

- Only 21 were childless, 99 having children in their household. 


\subsection{Methodology concerns}

Our research method is the comparative analysis (Walk, 1988). The results got from two surveys are juxtaposed. The key principle of the method is taking the raw data, considering their observed similarities and differences and making them cohere into a meaningful argument.

The group members live in different countries. We do not see this fact as something which could influence our future conclusions substantially:

a) Both surveys were done in the same period - on the peak of the second pandemic wave during the spring 2021. Their participants were equally affected by the lockdown and could not perform their duties in their standard ways.

b) The questionnaires addressed the issues of quality of their work and external conditions which may affect it. In the case of educators, they were their past preparation and adaption to online education from the point of the performance of educational activities. The employees were asked about the organization of their duties and the comfort/discomfort during their execution. In many ways, they act similarly because their outcome were only limited by their local conditions (quality of their Internet connection, the size of flat, the number of children, and the presence of their partners etc.). These factors were included in the second survey.

\section{Results}

Despite the fact that e-working and e-learning were already well known and have been part of working and educational environment, but the quick adaptation due the COVID-19 was challenging to work and to teach from home premises. Suddenly we are facing a digital tsunami dedicated to e-learning and e-working. From the two questionnaires we have selected to this paper only these responses which are related to the educational partners' roles: The readiness of university teachers to teach online and the readiness of employees to be taught online.

\subsection{Online Educators' Survey Results}

Prior the pandemic, only 41 out of 172 Czech and Slovak university educators used to work online regularly, next 42 used it occasionally and 88 had no previous experience with online teaching. Atop of it, only 55.2\% (95 educators) underwent some training prior the pandemic, with 32 among them (i.e. $18.6 \%$ of total) more than once. Of course, this means that remaining 77 lecturers can be considered unprepared for online education in the moment of pandemic breakout. Even worse, among 95 trained educators completing at least one training, 52 have never taught online prior the pandemic. From 32 of them who passed more than one training, 10 never taught online.

As a result, the question comes into mind: How long took them to get their regular education rhythm after the interruption of classroom education? Three responses were offered: one week - three weeks - not before the end of semester/trimester. The results indicates that they did a remarkable job. Only $5.8 \%$ of them were unable to get back to the work rhythm till the term end. It also indicates their high degree of teacher's flexibility and gives a high probability that during the next pandemic waves the business might run as usual soon after their breakout.

In general, the less experienced educators needed a longer average period to adapt. Out of 89 teachers who did not teach online before the pandemic, $59(66.2 \%)$ were able to capture their rhythm within a week, $23(25.8 \%)$ within three weeks and seven $(7.8 \%)$ of them did not do during their first term. $73.8 \%$ occasional online educators adapted in one week, $19 \%$ in 
three weeks and $7.1 \%$ not during the term. As one expects, the shortest adaption periods was needed in the regularly teaching online group. $90.2 \%$ of them adopted instantly, less than $10 \%$ needed more than one week, with no one getting lost. It implies that the groundwork pays off.

On the other hand, the question addressing their future activities offer a mixed picture. Some are quite positive. For example, $85.5 \%$ of teachers say that they will certainly or likely exploit their online education experience in their daily courses. Only $14.5 \%$ of them do not feel any sufficient inspiration. Similarly, $85.4 \%$ is ready to implement some ideas proposed by the students in their future course contents regardless whether online or in-class ones.

Still, there is still some uncertainty about the future of online education. Four out of five educators certain or likely certain that the proportion of the online education will grow in the future. In contrary, the majority sees it as a temporary replacement of the traditional teaching mode. $7.6 \%$ are certain that it is a temporary replacement and $45.7 \%$ consider it is likely. Only $9.9 \%$ educators strongly oppose to consider online education as a temporary replacement.

\subsection{E-working Professionals' Survey Results}

In the past, three quarters of employees participated in online courses. This means that except of remaining $25 \%$ of them, they can speak on behalf of "experienced online students". Their overall view to online education is positive. $60 \%$ of the respondents highlight they would welcome additional training in the future. In their opinion, schools and universities are still not ready to follow the progress of e-working. The most of teaching should be done using the hybrid education mode (combination online and on-site), as respondents (70\%) believe that this is the best solution for students. They are aware of potential difficulties because $40 \%$ of them believe that online learning is more challenging than traditional onsite learning. They also agree that the education system need to invest in the Information and Communication Technology to be ready for offering and teaching online courses.

Having experience with remote working, they also stress the importance of creating their home office environment (conducive, productive and still ergonometric). In a way, they have been interested in it even more than in their company's workplace. Two fifth of the respondents are facing some difficulties or limitations that make face-to-display work complicated or impossible i.e. just $40 \%$ of the employees would like to work at cubicles after pandemic. The vast majority say that would like to work remotely. 30\% prefer hybrid basis (partly at home and partly in cubicles) and 30\% full e-working.

They underline the importance of the increase in e-working working model being legally defined and controlled (Beňo and Hvorecký, 2021). 65\% of full-time professionals believe that e-working model should be regulated by law. On the contrary, $35 \%$ of them think no legal actions are needed. Notice that this issue can also be in interests of educators.

\section{Discussion}

Is e-learning and e-working here to stay? Regarding the e-learning activities, $8 \%$ of EU citizens followed an online course in 2019 (Eurostat, 2020a). In 2019, 28\% of young people aged 16 to 24 reported participating online (Eurostat, 2020b). Thus, this type of education becomes more and more important to the young generation. One can guess that its importance will grow with future generations of "digital natives". Slovakian data show that in 2017 only $3.4 \%$ participated in lifelong learning compared to the European Union average of $10.9 \%$ (Ministerstvo školstva, vedy, výskumu a športu (2018). The EU plans presumed 15\% of adults between 18 and 64 years to participate in it in 2020. The actual figures are not available yet but the pandemic transfer to the cyberspace likely speeded up the process and made many 
people aware about importance of online learning. It implies that there is a growing market for online education. From this point of view, the position of Slovak educators is a bad sign - its majority presumes that the online education is just a temporary replacement of more traditional methods. Even the proportion among teachers 20-39 years old is still 50:50. It does not offers big hopes for the future.

As we shown above, the online courses are highly valued by e-workers: $70 \%$ supporters is a big portion. It is natural because they are aware that this format simplifies their participation in education, expands their knowledge and facilitates their skills i.e. promotes their career.

Using asynchronous e-learning methods are more appropriate to them because they can be more easily combined with their working and family duties. Again, using synchronous teaching methods during the pandemic means lower experience and skills in the asynchronous ones preferred by busy people.

In 2019 , only $5.3 \%$ of employed in the EU-28 usually worked from home (Eurostat, 2020c). But the pandemic demonstrated the importance of e-working. Further, Data from 2019 confirm that older age groups prefer more face-to-display working compared to younger generation (Eurostat, 2020d). Clancy (2020) highlights that to skill up the kind of people who would most benefit from remote work, we need to offer online degree programs and add that the kinds of students who excel at online education are more likely to excel as remote workers too. More research is needed to develop the right policies, regulations to ensure the students, employees reap full benefits of e-learning and working. Because the impact of e-working is not equal divided around the globe among different types of employees including age, gender, education, skills and occupational structures (Beno, 2021, p. 5). As stated by Beňo et al. (2019) economic achievements alone are not enough to achieve a top ranking in tertiary education. As a result, the proportion of e-working will grow in the future. The universities should react to the trend and offer their courses in both on-site and online versions. This would help the students to get relevant habits and skills i.e. be better prepared for their future jobs.

\section{Conclusion}

The pandemic forced us to make a rapid switch to online communication. Even e-learning and e-working were settled in some of the organizations yet, it was still challenging to adapt to a shutdowns reality. It enforced a quick transition to work, teach and learn from home premises.

Based on our data, both teaching and working may collaborate. There was uncertainty about the efficiency of working and learning remotely. Among the employees, $65 \%$ of respondents believe that e-working model should be regulated by law. $40 \%$ are facing some difficulties with face-to-display work. Only $40 \%$ of the employees would like to work at cubicles after the pandemic, $30 \%$ prefer hybrid and $30 \%$ full e-working. $75 \%$ of employees participated in online courses. $70 \%$ of employees recommend hybrid education (combination of online and on-site) as the best solution. $40 \%$ of them believe that online learning is more challenging compared to traditional onsite learning. By them (45\%), schools and universities are not prepared for e-learning. $60 \%$ of the respondents highlight that education system needs to invest in the ICT to be ready for offering and teaching online courses.

This study has some limitations. Firstly, data collection took place by means of electronic questionnaires because of distance, financial aspects and Covid-19. There is no guarantee that the researchers drew all possible information from the participants that could be used in the analysis of the data and results. Also, the groups are quite distinct and the mixture of their opinions bears a risk of misunderstanding and/or misinterpretation. Secondly, the researchers have no way of ascertaining whether the respondents replied honestly or not. It should be 
stated that results from this study do not necessarily reflect how workers used to get to work will evolve in the post-pandemic period. Lastly, no sample reflects the population by their sectoral structure. For this reason authors plan to continue their research by adopting more specific and targeted tools and study samples. Nevertheless, the current comparative analysis gives them many impulses for their continuing studies and opens promising perspectives. At least, it has already shown that there should exist efforts to enhance online education is in the interest of both universities and companies.

\section{References}

1. Anttiroiko, A. (2021). Successful government responses to the pandemic: contextualizing national and urban responses to the COVID-19 outbreak in East and West. International Journal of E-Planning Research (IJEPR), 10(2), 1-17.

2. Beňo, M. (2021). Commuting to work versus e-commuting: Data from an Austrian company in Pre-COVID-19 era, during 1st lockdown, after easing and during 2nd lockdown. Ad Alta: Journal of Interdisciplinary Research, 11(1), 25-31.

3. Beno, M. (2021). Analysis of three potential savings in e-working expenditure. Frontiers in Sociology, 6(675530), 1-8.

4. Beňo, M., Ferenčíková, S., Hvorecký, J., \& Terek, M. (2019). Relations between public moral, academic ethics and university system's quality. Proceedings of the International Conference Theory and Applications in the Knowledge Economy TAKE 2019 - Vienna, 145-158.

5. Beňo, M., \& Hvorecký, J. (2021). Linkages between PISA results and e-working. Emerging Science Journal, 5(3), 294-304.

6. Beňo, M., Hvorecký, J., \& Šimúth, J. (2021). E-panopticon of face-to-display workers: From the office to the home. Ad Alta: Journal of Interdisciplinary Research, 11(1), 97105.

7. Eurostat. (2020a, October 14). Individuals - internet activities. http://appsso.eurostat.ec.europa.eu/nui/show.do?query=BOOKMARK_DS-

053730_QID_-140ED59C_UID_-

3F171EB0\&-̄ayout $=$ INDIC_IS,L,X,0;TIME,C,X,1;GEO,L,Y,0;UNIT,L,Z,0;IND_TYP

E,L,Z,1;INDICATORS,C,Z,2;\&zSelection=DS-

053730INDICATORS,OBS_FLAG;DS-053730UNIT,PC_IND;DS-

053730IND_TYPE,IND_TOTAL;\&rankName1=UNIT_1_2 -

1_2\&rankName2=INDICATORS_1_2_-1_2\&rankName3 $=\overline{-}$ IND-TYPE_1_2_-

1 2\&rankName4=INDIC-

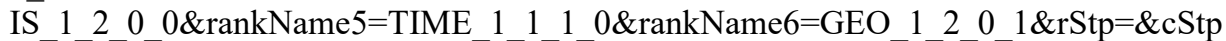
$=\& \mathrm{rDCh}=\& \mathrm{cDCh}=\& \mathrm{rDM}=$ true $\& \mathrm{cDM}=$ true $\&$ footnes $=$ false $\&$ empty $=$ false $\&$ wai $=$ false $\&$ time_mode $=$ ROLLING\&time_most_recent $=$ true \&lang $=E N \& c f o=\% 23 \% 23 \% 23 \% 2 \mathrm{C} \%$ $23 \% \overline{2} 3 \% 23 . \% 23 \% 23 \% 23$

8. Eurostat. (2020b, October 14). Individuals - internet activities. http://appsso.eurostat.ec.europa.eu/nui/show.do?query=BOOKMARK_DS053730_QID_AAB299_UID_-

3F171EB0\&layout $=$ INDIC_IS,L,X,0;TIME,C,X,1;IND_TYPE,L,Y,0;UNIT,L,Z,0;GE O,L,Z,1;INDICATORS,C,Z,2;\&zSelection=DS-

053730INDICATORS,OBS_FLAG;DS-053730GEO,EU27_2020;DS-

053730UNIT,PC_IND;\&rankName1=UNIT_1_2_-

1_2\&rankName2=INDICATORS_1_2_-

1_2\&rankName3=GEO_1_2_1_1\& $\overline{\mathrm{rank}} \overline{\mathrm{k}} \mathrm{Name} 4=\mathrm{INDIC}-$ 
IS 1_2_0_0\&rankName5=TIME_1_1_1_0\&rankName6=IND-

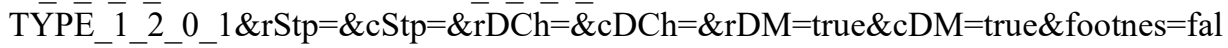 se\&empty $=$ false \&wai $=$ false\&time_mode $=$ ROLLING\&time_most_recent $=$ true\&lang $=$ $\mathrm{EN} \& \mathrm{cfo}=\% 23 \% 23 \% 23 \% 2 \mathrm{C} \% 23 \% 23 \% 23 . \% 23 \% 23 \% 23$

9. Eurostat. (2020c, November 11). Employed persons working from home as a percentage of the total employment, by sex, age and professional status (\%). https://ec.europa.eu/eurostat/databrowser/view/lfsa_ehomp/default/table?lang=e

10. Eurostat. (2020d, November 11). Employed persons working from home as a percentage of the total employment, by sex, age and professional status. https://appsso.eurostat.ec.europa.eu/nui/show.do?query=BOOKMARK_DS-

052914 QID -50734B6 UID -

3F171EB0\&layout=TIME,C, $\bar{X}, 0 ;$ GEO,L,Y,0;SEX,L,Z,0;FREQUENC,L,Z,1;AGE,L,Z ,2;WSTATUS,L,Z,3;UNIT,L,Z,4;INDICATORS,C,Z,5;\&zSelection=DS-

052914WSTATUS,EMP;DS-052914FREQUENC,USU;DS-

052914INDICATORS,OBS_FLAG;DS-052914AGE,Y15-64;DS-052914SEX,T;DS-

052914UNIT,PC;\&rankName1=WSTATUS_1_2_-1_2\&rankName2=UNIT_1_2_-

1_2\&rankName3=AGE_1_2_-1_2\&rankName4=FREQUENC_1_2_-

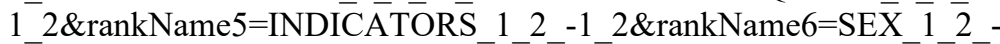

1_2\&rankName 7=TIME_1_0_0_0\&rankName8 $=\mathrm{GEO} 112$ 2_0_1\&sortC $=\mathrm{ASC}$ -

1 FIRST\&rStp $=\& \mathrm{cStp}=\overline{\mathrm{\&}} \mathrm{rD} \overline{\mathrm{C} h}=\& \mathrm{cDCh}=\& \mathrm{rDM}=$ true $\& \mathrm{cD} \overline{\mathrm{M}}=\overline{\text { true }} \&$ footnes $=\overline{\text { false }} \& \mathrm{e}$

mpty $=$ false\&wai $=$ false\&time_mode $=$ FIXED\&time_most_recent $=$ false\&lang $=$ EN\&cfo $=\% 23 \% 23 \% 23 \% 2 \mathrm{C} \% 23 \% 23 \% 23 . \% 23 \% 23 \% 23$

11. Clancy, M. (2020, April 13). The Case for Remote Work. https://lib.dr.iastate.edu/cgi/viewcontent.cgi?article=1101\&context=econ_workingpape rs

12. Eurostat (2021, September 10). Employed persons working from home as a percentage of the total employment, by sex, age and professional status (\%).https://ec.europa.eu/eurostat/databrowser/view/lfsa_ehomp/default/table?lang=en

13. Henry, M. S., Le Roux, D. B., \& Parry, D. A. (2021). Working in a post Covid-19 world: Towards a conceptual framework for distributed work. South African Journal of Business Management, 52(1), a2155.

14. Hopikins, J. L., \& McKay, J. (2019). Investigating 'anywhere working' as a mechanism for alleviating traffic congestion in smart cities. Technological Forecasting and Social Change, 142, 258-272.

15. Karim, M. R., Islam, M. T., \& Talukder, B. (2020). COVID-19's impacts on migrant workers from Bangladesh: In search of policy intervention. World Development, 136, 105123.

16. Madero Gómez, S., Ortiz Mendoza, O. E., Ramírez, J., \& Olivas-Luján, M. R. (2020). Stress and myths related to the COVID-19 pandemic's effects on remote work. Management Research, 18(4), 401-420.

17. Ministerstvo školstva, vedy, výskumu a športu (2018). Kvalitné a dostupné vzdelanie pre Slovensko: Národný program rozvoja výchovy a vzdelávania. Bratislava, 59.

18. Roca-Puig, V. (2019). The circular path of social sustainability: An empirical analysis. Journal of Cleaner Production, 212, 916-924.

19. Stofkova, Z., \& Sukalova, V. (2020). Sustainable development of human resources in globalization period. Sustainability, 12(18), 7681.

20. Walk, K. (1988). How to write a comparative analysis. harvard college writing center. Available: https://writingcenter.fas.harvard.edu/pages/how-write-comparative-analysis. 